\title{
Effects of a Blended Chinese Medicine, Xiao-Chai-Hu-Tang, on Lewis Lung Carcinoma Growth and Inhibition of Lung Metastasis, with Special Reference to Macrophage Activation
}

\author{
Hitoshi ITO and Keishiro SHIMURA* \\ Department of Pharmacology and *Institute of Laboratory Animals, \\ Mie University School of Medicine. Tsu, Mie 514. Japan \\ Accepted March 24, 1986
}

\begin{abstract}
The antitumor effects of Xiao-Chai-Hu-Tang (Shōsaiko-Tō: SHX) with or without 5-fluorouracil (5-FU) or cyclophosphamide (CY) were examined in an experimental system of lung metastasis induced by Lewis lung carcinoma in C57BL/ 6 crSlc mice. Lewis lung carcinoma cells were implanted into the footpads of the mice. Ten days later, the implanted tumors were surgically removed. The effects of SHX were evaluated by the number of lung surface nodules present 14 days after removal of the implanted tumor. The administration of SHX, p.o. $(300 \mathrm{mg} / \mathrm{kg} \times 2 /$ day $\times 10$ ) caused the antimetastatic effect. Therapy with SHX plus 5 - FU or CY significantly inhibited the development of lung metastases. The number of peritoneal macrophages and the degree of the binding of $\mathrm{C} 3$ cleavage products (C3b) to macrophages were enhanced in the mice treated with SHX. Lung metastases were inhibited by the i.v. administration of peritoneal macrophages activated with SHX, p.o. These findings raise the possibility that $\mathrm{SHX}$ may have clinical value in the prevention of cancer metastasis.
\end{abstract}

The pathogenesis of cancer metastasis involves many complicated biological steps. Its outcome depends on the interaction of tumor cells with their host and is influenced by various factors at each stage of metastasis (1). Metastasis begins with the local invasion of the surrounding host tissue by cells from the primary tumor. This is done by single cells, cell clumps or multi-cellular tongues (2). The functioning of host defenses in the control of metastasis is not known precisely. Increased metastasis observed after either generalized immunosuppression (3-5) or the suppression of T-cell activity (6) and/or macrophages (7) indicates that these components of the immune system play roles in controlling metastasis. Thus, it might be possible to eradicate or prevent metastases by immunologically adjusting host defense mechanisms.

Recently, so-called biological response modifiers (BRM) such as BCG (8), BCG cell wall skeleton (9). Nocardia rubra cell wall skeleton (10), Corynebacterium parvum (11), glucans isolated from basidiomycetes (12. 13), and muramyl dipeptide (14) that activate the reticuloendothelial system have been found to inhibit the development of metastasis.

The present study was undertaken to investigate the effects of SHX on Lewis lung carcinoma growth and inhibition of lung metastasis. The role of macrophages in inhibiting the growth of Lewis lung carcinoma is discussed.

\section{Materials and Methods}

Animals: Five-week-old females C57BL/ 6crSlc (SPF), weighing 19 to $22 \mathrm{~g}$, were obtained from the Shizuoka Laboratory Animal Center. They were maintained on an NMF diet with water throughout the experiments.

Tumor: Lewis lung carcinoma was initially supplied by the Aichi Cancer Center Institute. It was maintained by serial biweekly s.c. 
passage in $\mathrm{C} 57 \mathrm{BL} / 6 \mathrm{crSlc}$ mice. The tumor fragments (minced solid mass of tumors) were stirred in RPMI medium 1640 (Gibco Laboratories, Grand Island Biological Co., Grand Island, N.Y.), containing $0.05 \%$ trypsin, at $37^{\circ} \mathrm{C}$ for $30 \mathrm{~min}$. After rinsing, the viability of the tumor cells was confirmed by the trypan blue dye exclusion method. A suspension of $10^{5}$ viable cells in $0.05 \mathrm{ml}$ of RPMI 1640 was implanted s.c. into each mouse, in either its axillary region or footpad.

Drugs: The constituents of Shōsaiko-Tō (SHX) are shown in Table 1. SHX has been effectively used for the therapy of hepatic disorders (chronic active hepatitis, postoperative liver complication) bronchial asthma, gastrointestinal disturbances and pneumonia. Aqueous extracts of SHX were provided from Tsumura Research Institute. The required concentrations of SHX were dissolved in $0.9 \%$ physiological saline for the study. An antitumor agent, 5-fluorouracil (5-FU, Kyowa Hakko Kogyo Co., Ltd.) or cyclophosphamide (CY, Shionogi \& Co., Ltd.), was used as a reference drug in some of the experiments.

Assay of antitumor activity: For the early Lewis lung carcinoma system, tumor growth inhibition was determined by comparing the mean survival time of the treated animals ( $T$ ) with that of the control (saline-treated) tumor-bearing animals $(\mathrm{C})$. The percentage increase in life span $(\mathrm{T} / \mathrm{C} \%)$ was measured by the method we reported previously (15). As for the lung metastasis system: 10 days after implantation. when the tumor $\left(10^{5}\right.$ cells/mouse) implanted in the footpad had become about 4 to $5 \mathrm{~mm}$ in diameter, each mouse was anesthetized by i.p. injection of
$1 \mathrm{mg}$ of sodium pentobarbital (Nembutal). The tumor-bearing leg was then surgically amputated. Lung metastasis was estimated 14 days after removal of the implanted primary tumor. The gross number of metastatic nodules was counted by Wexler's method (16).

Preparation of effector cells: Peritoneal exudate cells (PEC) were collected by washing the peritoneal cavity with $10 \mathrm{ml}$ of RPMI 1640, 5 days after p.o. administration of the SHX. The adherent cells and nonadherent cells of the PEC $\left(5 \times 10^{5} /\right.$ mouse $)$ were isolated by the method of Kumagai et al. (17).

Phagocytosis and C3 cleavage product binding assay: Some of the mice were administered p.o. $300 \mathrm{mg} / \mathrm{kg}$ of SHX twice a day, for 10 days. The control mice received only saline. The peritoneal macrophages were obtained as described above (17). The number of adherent cells was determined by wells. After extensive washing, a 0.25 $\mathrm{mm}^{2}$ area that included several different well areas was routinely counted (18). The adherent cells $\left(4 \times 10^{5}\right)$ on the coverslips were dried and then fixed in 95\% ethanol for $20 \mathrm{~min}$. Next they were dried again, covered with anti-mouse C3 $\mathrm{F}\left(\mathrm{ab}^{\prime}\right)_{2}$ (prepared by treating anti-mouse $\mathrm{C} 3$ rabbit $\operatorname{lgG}$ with pepsin) and reincubated for $1 \mathrm{hr}$ at $37^{\circ} \mathrm{C}$. After the incubation, the cells were rinsed thoroughly with PBS ( $\mathrm{pH}$ 7.2) and stained with goat FITC-anti-rabbit IgG at room temperature for $1 \mathrm{hr}$. Then they were washed thoroughly again with PBS ( $\mathrm{pH}$ 7.2). mounted in a buffered glycerol $(\mathrm{pH} 9.5)$. and examined under a microscope $(\times 400)$. About 200 adherent cells were counted on

Table 1. Constituents of SHX

\begin{tabular}{lc}
\hline Crude drug & Proportion \\
\hline Bupleuri R. & 7.0 \\
Pinelliae T. & 5.0 \\
Scutellariae R. & 3.0 \\
Zizyphi F. & 3.0 \\
Ginseng R. & 3.0 \\
Glycyrrhizae R. & 2.0 \\
Zingiberis Rh. & 1.0 \\
\hline
\end{tabular}

Shosaiko-To (SHX) was prepared by blending the proportions of drugs indicated in the Table. 
each slide. Based on this, the percentage of C3-positive fluorescent cells was calculated (18).

Statistical differences between the control and experimental treated groups were evaluated by using Student's $t$-test.

\section{Results}

Antitumor effects of SHX against early Lewis lung carcinoma: The influence of the route of SHX administration on the inhibition of Lewis lung carcinoma growth was examined. As shown in Table 2, the oral administration of SHX resulted in a $120 \%$ $\mathrm{T} / \mathrm{C} \%$ when a dose of $300 \mathrm{mg} / \mathrm{kg} \times 2 /$ day was given for 10 consecutive days. However, with SHX doses of $150 \mathrm{mg} / \mathrm{kg} \times 2 /$ day and $600 \mathrm{mg} / \mathrm{kg} \times 2 /$ day, the antitumor effect was decreased. These results indicate that there is an optimal dose of SHX for inhibiting the growth of Lewis lung carcinoma. SHX had no inhibitory effect when injected i.p. into mice.

Antitumor effects of 5-FU and $\mathrm{CY}$ against early Lewis lung carcinoma: The results of using 5-FU and CY to treat early Lewis lung carcinoma are shown in Table 3 . The deviation of survival time among 12 tumor bearing mice was $24.9 \pm 1.7$ (S.E.) days. Antitumor activity was determined from the ratio of

Table 2. Effects of different routes of SHX administration on early Lewis lung carcinoma system

\begin{tabular}{|c|c|c|c|c|c|}
\hline \multirow{2}{*}{ Treatmenta } & \multirow{2}{*}{\multicolumn{2}{|c|}{$\begin{array}{c}\text { Dose (Route) } \\
\text { (mg/kg/day) }\end{array}$}} & \multicolumn{2}{|c|}{ Survival time } & \multirow{2}{*}{ Incidence ${ }^{c}$} \\
\hline & & & Days & $\%^{b}$ & \\
\hline Control & & & $25.7 \pm 1.4^{d}$ & 100 & $6 / 6$ \\
\hline \multirow[t]{3}{*}{ SHXe } & $150 \times 2$ & (p.o.) & $26.1 \pm 0.9$ & 102 & $6 / 6$ \\
\hline & $300 \times 2$ & (p.o.) & $30.8 \pm 1.8^{*}$ & 120 & $6 / 6$ \\
\hline & $600 \times 2$ & (p.o.) & $27.6 \pm 1.1$ & 107 & $6 / 6$ \\
\hline \multirow[t]{2}{*}{$S H X^{f}$} & 100 & (i.p.) & $26.0 \pm 1.2$ & 101 & $6 / 6$ \\
\hline & 300 & (i.p.) & $20.3 \pm 1.1$ & 79 & $6 / 6$ \\
\hline
\end{tabular}

alnoculum of $10^{5}$ tumor cells was implanted s.c. into the axillary region of each mouse. bSurvival time of the treated group expressed as a percentage of survival time of the controls. cNumber of mice with lung metastasis compared to number of mice tested. aMean \pm S.E. eSHX was administered p.o. twice a day for 10 days, starting $24 \mathrm{hr}$ after tumor implantation. fSHX was administered i.p. once a day for 10 days, starting $24 \mathrm{hr}$ after tumor implantation. ${ }^{*} \mathrm{P}<0.05$ compared with control group.

Table 3. Effects of $5-\mathrm{FU}$ and $\mathrm{CY}$ on early Lewis lung carcinoma system

\begin{tabular}{|c|c|c|c|c|c|}
\hline \multirow{2}{*}{ Treatmenta } & \multirow{2}{*}{\multicolumn{2}{|c|}{$\begin{array}{c}\text { Dose (Route) } \\
(\mathrm{mg} / \mathrm{kg} / \mathrm{day})\end{array}$}} & \multicolumn{2}{|c|}{ Survival time } & \multirow{2}{*}{ Incidence } \\
\hline & & & Days & $\%^{b}$ & \\
\hline Control & & & $24.9 \pm 1.7^{\mathrm{d}}$ & 100 & $6 / 6$ \\
\hline \multirow[t]{4}{*}{ 5-FUe } & 10 & (p.o.) & $25.0 \pm 0.8$ & 100 & $6 / 6$ \\
\hline & 20 & (p.o.) & $31.4 \pm 1.9^{*}$ & 126 & $5 / 6$ \\
\hline & 30 & (p.o.) & $34.1 \pm 2.1^{*}$ & 137 & $5 / 6$ \\
\hline & 50 & (p.o.) & $28.9 \pm 1.1$ & 116 & $2 / 6$ \\
\hline \multirow[t]{4}{*}{$C Y^{\circ}$} & 10 & (p.o.) & $29.1 \pm 1.1$ & 117 & $5 / 6$ \\
\hline & 20 & (p.o.) & $34.9 \pm 2.7^{*}$ & 140 & $4 / 6$ \\
\hline & 30 & (p.o.) & $46.6 \pm 3.6^{*}$ & 187 & $1 / 6$ \\
\hline & 50 & (p.o.) & $17.2 \pm 0.7$ & 69 & toxic \\
\hline
\end{tabular}

"Inoculum of $10^{5}$ tumor cells was implanted s.c. into the axillary region of each mouse. bSurvival time of the treated group expressed as a percentage of survival time of the controls. cNumber of mice with lung metastasis compared to number of mice tested. dMean \pm S.E. eCyclophosphamide (CY) or 5 fluorouracil (5-FU) was administered p.o. three times a week until death, starting 24 hr after tumor implantation. ${ }^{*} \mathrm{P}<0.05$ compared with control group. 
median life-span between the treated and control groups. CY was markedly active. causing an increase in life-span of $87 \%$ (over controls) at $30 \mathrm{mg} / \mathrm{kg} /$ day. With $\mathrm{CY}$ at $20 \mathrm{mg} / \mathrm{kg} /$ day, median life-span increased by $40 \%$. $5-\mathrm{FU}$ at $30 \mathrm{mg} / \mathrm{kg} /$ day caused an increase of $37 \%$. CY was more effective than 5-FU at similar doses. However, the median survival time of mice treated with $50 \mathrm{mg} / \mathrm{kg} /$ day of CY was shorter than that of controls.

All animals were autopsied at death and observed for gross evidence of Lewis lung tumors. Nearly all of the mice in the control group showed gross lung tumor involvement. No metastatic nodules could be seen in 5 of 6 mice treated with $30 \mathrm{mg} / \mathrm{kg} /$ day of $\mathrm{CY}$ (the optimal dose), whereas it was observed in 4 of 6 mice treated with $50 \mathrm{mg} / \mathrm{kg} / \mathrm{day}$ of 5 -FU (higher than the optimal dose). CY was more effective than 5-FU, both in the suppression of tumor growth and in the prevention of lung metastasis.

Additive effects of $\mathrm{SHX}$ and 5-FU or $\mathrm{CY}$ on lung metastasis: The effects of combining SHX with 5-FU or CY to inhibit the metastasis of Lewis lung carcinoma were examined. The drugs were given p.o. after removal of the implanted primary tumor. As shown in Table 4, the development of lung metastasis was inhibited by each of these treatments when administered singly. The effects of treatment with 5-FU or CY were additive. No metastatic nodules at all were seen in 5 of the 7 mice treated with SHX plus $\mathrm{CY}$. Combined therapy with SHX plus 5-FU, significantly decreased the mean number of metastatic nodules visible in the lung.

Effects of i.v. injection of peritoneal macrophages activated with $\mathrm{SHX}$ on lung metastasis: Peritoneal adherent cells activated with SHX (as described above) were injected i.v. into mice lung metastases on Days 10. 12 and 14 after tumor implantation. As shown in Table 5, a significant reduction in the number of metastatic nodules was observed in the lungs of mice given injections of peritoneal adherent cells activated with SHX, but not in mice given injections of nonadherent cells treated with SHX. Furthermore, no inhibition of metastasis was seen in mice given injections of peritoneal adherent cells taken from normal mice. These results indicate that the transfer of peritoneal macrophages activated with SHX has an inhibitory effect on lung metastasis.

Effects of SHX on macrophage accumulation and induction of $\mathrm{C} 3$-positive macrophages: The dose of $\mathrm{SHX}$ used in this experiment is based on the antitumor effects observed in vivo. The maximum antitumor effect occurred after p.o. administration of $300 \mathrm{mg} / \mathrm{kg} \times 2 /$ day to Lewis lung carcinomabearing mice. As shown in Table 6, a marked accumulation of macrophages in the peritoneal cavity was observed $5-7$ days after

Table 4. Effects of SHX with and without 5-FU or CY on advanced Lewis lung carcinoma

\begin{tabular}{|c|c|c|c|c|}
\hline \multirow{2}{*}{ Treatment: } & \multirow{2}{*}{$\begin{array}{c}\text { Dose (Route) } \\
(\mathrm{mg} / \mathrm{kg} / \text { day })\end{array}$} & \multicolumn{2}{|c|}{ Lung metastasis ${ }^{b}$} & \multirow{2}{*}{ Incidences } \\
\hline & & No. of surf & nodules & \\
\hline Control & & $30.5 \pm 4.1^{d}$ & $(22-46)^{e}$ & $12 / 12$ \\
\hline $5-F U$ & 30 (p.o.) & $18.3 \pm 3.1^{*}$ & $(0-31)$ & $5 / 6$ \\
\hline $\mathrm{CY}$ & 20 (p.o.) & $14.2 \pm 2.1^{*}$ & $(0-24)$ & $4 / 6$ \\
\hline SHX & $300 \times 2$ (p.o.) & $20.9 \pm 5.7^{*}$ & $(7-41)$ & $6 / 6$ \\
\hline $\mathrm{SHX}+5-\mathrm{FU}$ & $(300 \times 2)+30$ (p.o.) & $8.2 \pm 3.4^{* *}$ & $(0-27)$ & $5 / 7$ \\
\hline $\mathrm{SHX}+\mathrm{CY}$ & $(300 \times 2)+20$ (p.o.) & $3.9 \pm 2.1^{* *}$ & $(0-14)$ & $2 / 7$ \\
\hline
\end{tabular}

"Inoculum of $10^{5}$ tumor cells was implanted s.c. into one footpad of each mouse. The tumor was removed by amputating the tumor-bearing leg on Day 10 after tumor implantation. Treatment was started from the day of tumor removal, with drugs being administered p.o. for 14 days, three times a week (5-FU or CY). or twice a day $(\mathrm{SHX})$. bLung metastasis was estimated 14 days after removal of the implanted tumor. cNumber of mice with lung metastasis compared to number of mice tested. dMean \pm S.E. eRange of the number of surface nodules. ${ }^{*} P<0.05$ compared with controls (undergoing amputation only). $\quad{ }^{*} P<0.05$ compared with use of $5-F U$ or CY by itself. 
Table 5. Effects of i.v. transfer of adherent cells from PEC activated with SHX on lung metastasis

\begin{tabular}{|c|c|c|c|}
\hline \multirow{2}{*}{ Treatmenta } & \multicolumn{2}{|c|}{ Lung metastasis ${ }^{b}$} & \multirow{2}{*}{ Incidence ${ }^{c}$} \\
\hline & No. of sur & nodules & \\
\hline Control & $32.7 \pm 4.9 \mathrm{~d}$ & $(12-41)^{e}$ & $6 / 6$ \\
\hline Normal adherent PEC & $30.1 \pm 5.3$ & $(21-43)$ & $6 / 6$ \\
\hline SHX-activated nonadherent PEC & $28.7 \pm 4.7$ & $(20-39)$ & $6 / 6$ \\
\hline SHX-activated adherent PEC & $24.1 \pm 3.2^{*}$ & $(9-33)$ & $6 / 6$ \\
\hline
\end{tabular}

a noculum of $10^{5}$ tumor cells was implanted s.c. into one footpad of each mouse. The tumor was removed by amputating the tumor-bearing leg on Day 10 after tumor implantation. Peritoneal exudate cells (PEC) were collected 5 days after p.o. administration of $\mathrm{SHX}(300 \mathrm{mg} / \mathrm{kg}$ twice a day). Adherent or nonadherent cells taken from the PEC $\left(5 \times 10^{5}\right)$ were injected i.v. on Days 10,12 and 14 after tumor implantation. bLung metastasis was estimated 14 days after removal of the implanted tumor. cNumber of mice with lung metastasis compared to number of mice tested. dMean \pm S.E. eRange of the number of surface nodules. ${ }^{*} \mathrm{P}<0.05$ compared with controls (undergoing amputation only) and also compared with normal adherent PEC.

Table 6. Macrophage accumulation in peritoneal cavity and induction of C3-positive fluorescent cells treated with SHX

\begin{tabular}{|c|c|c|c|c|}
\hline \multirow{2}{*}{ Treatmenta } & \multicolumn{4}{|c|}{ Number of peritoneal macrophages $\left(\times 10^{6}\right)$ per mouse ${ }^{b}$} \\
\hline & 3 days & 5 days & 7 days & 10 days \\
\hline Control & $2.1 \pm 0.2$ & $1.5 \pm 0.3$ & $2.0 \pm 0.5$ & $2.0 \pm 0.5$ \\
\hline \multirow[t]{2}{*}{$\mathrm{SHX}$} & $2.6 \pm 0.4$ & $4.2 \pm 1.3$ & $3.7 \pm 0.4$ & $2.9 \pm 0.6$ \\
\hline & \multicolumn{4}{|c|}{ Percentage of C3-positive fluorescent cells ${ }^{c}$} \\
\hline Control & $3.6 \pm 0.5$ & $4.6 \pm 1.7$ & $9.6 \pm 2.1$ & $8.0 \pm 1.6$ \\
\hline $\mathrm{SHX}$ & $29.0 \pm 7.5$ & $60.3 \pm 10.3$ & $65.0 \pm 4.5$ & $34.3 \pm 5.7$ \\
\hline
\end{tabular}

a Peritoneal macrophages were obtained from mice treated with $300 \mathrm{mg} / \mathrm{kg}$ of SHX twice a day. Control macrophages were obtained from mice treated with $0.25 \mathrm{ml} /$ mouse of saline twice a day. bPeritoneal macrophages were counted according to the method described in the text. cAmong mouse peritoneal macrophages present on the coverslips after treatment with SHX or saline. Results are expressed as the mean \pm S.E. for 4 mice.

p.o. administration of the SHX. In contrast, the number of peritoneal macrophages seen in the mice who received saline did not increase during a 10-day period. As shown in Fig. 1, C3 cleavage caused many macrophages to be brightly positive in immunofluorescence after p.o. administration of the SHX. Table 6 shows that the C3-positive macrophages reached their maximum levels during Days 5-7. The macrophages were most brightly positive (about $65.0 \%$ of the cells) 7 days after SHX administration. However, in the control (saline) group, only $9.6 \%$ showed immunofluorescence on Day 7.

\section{Discussion}

The inhibition and prevention of metastasis are important problems in cancer therapy. It may be possible to inhibit metastasis, which is usually fatal in patients with malignant neoplasms. However, it is difficult to prevent overt metastasis or primary tumor growth. Some polysaccharides, zymosan (19). ATSO (20), GU-P (21), hemicellulose B (22), schizophyllan (23) and lentinan (24) isolated from plants or microorganisms have been reported to exert antitumor effects. Their antitumor effects usually manifest as the 

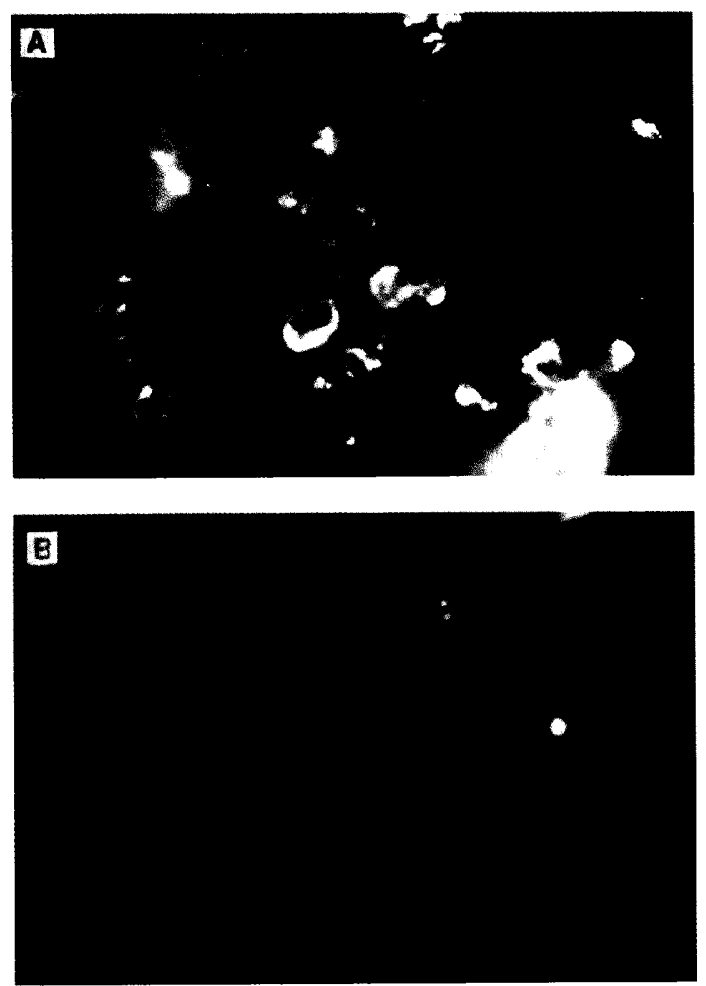

Fig. 1. Fluorescent photomicrographs $(\times 400)$ of C3 cleavage products present in peritoneal macrophages, 7 days after p.o. administration of: A (SHX $300 \mathrm{mg} / \mathrm{kg} \times 2 /$ day) or B (saline $0.25 \mathrm{ml}$ ).

ability to stimulate immunologic host defense mechanisms. There are also a few reports of the prevention of micrometastasis by BRM (8-14). Little is known, however, about the effects of traditional Chinese medicine. Although Kampō-prescriptions (mixtures of traditional Chinese drugs) have been given for various diseases since ancient times, their effectiveness is uncertain at present. We have already reported that $\mathrm{SHX}$ inhibits the growth of Ehrlich ascites carcinoma (25).

The present study was undertaken to investigate the effects of SHX on Lewis lung carcinoma growth and on the formation of blood-borne metastasis. By itself. SHX not only inhibited the growth of Lewis lung carcinoma, but also reduced the number of metastatic nodules in the lung. SHX is a unique substance in that it shows greater antitumor effects by oral administration than by parenteral administration.
$\mathrm{CY}$ and 5-FU were each effective in preventing lung micrometastasis in syngeneic mice after the removal of Lewis lung carcinoma implanted in the footpad. We also found that SHX plus $\mathrm{CY}$ or SHX plus $5-\mathrm{FU}$ had additive inhibitory effects on lung metastasis. The potency of SHX plus CY was greater than that of SHX plus 5-FU. These results are consistent with observations of the effects of CY and a glucan (schizophyllan) on Lewis lung carcinoma-bearing mice (26).

We also demonstrated that i.v. injections of peritoneal macrophages activated with SHX inhibited the development of lung micrometastasis. Thus, the antimetastatic activity and the antitumor effect of SHX on lung carcinoma seems to be mediated by the activation of macrophages. Ito et al. (27) reported that adherent peritoneal exudate cells, harvested from mice after i.p. injections of squalene-treated Nocardia rubra cell wall skeleton ( $\mathrm{N}$-CWS), showed cytolytic activity on tumor target cells in vitro. They also found that this activity was markedly inhibited by treatment with antimacrophage serum and complement or carrageenan. Moreover, Liotta et al. (28) reported that the i.v. transfer of BCG-activated peritoneal exudate cells inhibited lung metastasis in mice that had implanted $T_{241}$ fibrosarcomas. Furthermore, Sone et al. (29) demonstrated that after direct stimulation with N-CWS, alveolar macrophages became tumorcidal against syngeneic, allogeneic and xenogeneic tumor cells in vitro.

In the present study, lung metastasis was inhibited when the simultaneous administration of SHX and either 5-FU or CY followed the amputation of the tumor-bearing leg. Several interpretations of this are possible: 1) The cytotoxicity of CY or 5-FU was enhanced by the simultaneous administration of SHX. That is, treatment with a combination of $\mathrm{SHX}$ and $\mathrm{CY}$ or 5-FU exhibited an additive effect. 2) SHX may have negated the immunosuppressive effect of 5-FU, CY, or both 5-FU and $\mathrm{CY}$. Immunosuppression is one of the disadvantages of 5-FU and CY. 3) The tumor cells sterilized by 5-FU or $\mathrm{CY}$ might have released abundant antigens, which led to an enhanced immune response. 
Although the present findings do not clarify the mechanism involved in the combined effect, the experimental results indicate that SHX can serve as an excellent adjuvant to such chemotherapeutic drugs as 5-FU and $\mathrm{CY}$.

\section{References}

1 Poste, G. and Fidler, I.J.: The pathogenesis of cancer metastasis. Nature 283, 139-146 (1980)

2 Trinkaus, J.P.: The Cell Surface in Animal Embryogenesis and Development. Edited by Poste, G. and Nicolson, G.L., p. 225-329. North-Holland. Amsterdam (1976)

3 Carnaud, C., Hoch, B. and Trainin, N.: Influence of immunologic competence of the host on metastasis induced by the $3 \mathrm{LL}$ Lewis lung tumor in mice. JNCl 52, 395-399 (1974)

4 Makidono, R., Nomoto, K. and Takeya, K.: Enhanced development of metastatic foci in thymectomized, irradiated, and bone marrowreconstituted mice. Gann 67, 645-649 (1976)

5 Seshadri, M., Poduval, T.B. and Sundaram, K.: Studies on metastases. 1. Role of sensitization and immunosuppression. JNCl 63, 1205-1210 (1979)

6 Eccles, S.A., Styles, J.M., Hobbs, S.M. and Dean, C.J.: Metastases in nude rats associated with lack of immune resporise. Br. J. Cancer 40 , 802-805 (1979)

7 Jones, P.D.E. and Castro, J.E.: Immunological mechanism in metastatic spread and the antimetastatic effect of $C$. parvum. Br. J. Cancer 35, 519-527 (1977)

8 Kreider, J.W., Bartlett, G.L., Boyer, C.M. and Purnell, D.M.: Conditions for effective Bacillus Calmette-Guerin immunotherapy of post surgical metastases of $13762 \mathrm{~A}$ rat mammary adenoCárcinoma. Cancer Res. 39, 987-992 (1979)

9 Ogura, T., Namba, N., Hirao, F., Yamawaki, M., Azuma, I. and Yamamura, Y.: Effect of BCG cellwall skeleton on metastasis of syngeneic tumor in rats, with special reference to lymphocyte trapping. Gann 69, 311-315 (1978)

10 Kagawa, K., Yamashita, T., Tsubura, E. and Yamamura, $Y$.: Inhibition of pulmonary metastasis by Nocardia rubra cell wall skeleton, with special reference to macrophage activation. Cancer Res. 44, 665-670 (1984)

11 Mosley, J.G., Sadler, T.E. and Castro, J.E.: Effects of amputation and Corynebacterium parvum on tumor metastases in mice. Br. J. Cancer 37, 571-575 (1978)

12 Proctor, J.W., Auclair, B.G., Stokowski, L., Mansell, P.W.A. and Shibata, H.: Comparison of effects of BCG, glucan, and levamisole on B16 melanoma metastases. Eur. J. Cancer 13, 115122 (1977)

13 Usi, S., Urano, M., Koike, S. and Kobayashi, Y.: Effect of PS-K, a protein polysaccharide, on pulmonary metastases of a $\mathrm{C} 3 \mathrm{H}$ mouse squamous cell carcinoma. J NCI 56, 185-187 (1976)

14 Fidler, I.J., Sone, S., Fogler, W.E. and Barnes, Z.L.: Eradication of spontaneous metastases and activation of alveolar macrophages by intravenous injection of liposomes containing muramyl dipeptide. Proc. Natl. Acad. Sci. U.S.A. 78, 1680-1684 (1981)

15 Ito, H. and Hidaka, H.: Antitumor effect of a calmodulin antagonist on the growth of solid Sarcoma-180. Cancer Lett. 19, 215-220 (1983)

16 Wexler, $\mathrm{H}$.: Accurate identification of experimental pulmonary metastases. $\mathrm{JNCl} 36,641-645$ (1966)

17 Kumagai, K., Itoh, K., Hinuma, S. and Tada, M.: Pretreatment of plastic Petri dishes with fetal calf serum. A simple method for macrophage isolation. J. Immunol. Methods 29, 17-25 (1979)

18 Shimura, K., Ito, H., Hibasami, H., Shiomi, T., Hidaka, $\mathrm{H}$. and Nishioka, K.: Enhancement of antibody-independent phagocytosis by $\mathrm{N}-(6-$ aminohexyl) - 5-chloro - 1 - naphthalene - sulfon amide (W-7). Immunol. Commun. 12, 363-374 (1983)

19 Bradner, W.T., Clarke, D.A. and Stock, C.C.: Stimulation of host defense against experimental cancer. 1. Zymosan and sarcoma 180 in mice. Cancer Res. 18, 347-351 (1958)

20 Shimura, K., Ito, H. and Hibasami, H.: Screening of host-mediated antitumor polysaccharides by crossed immunoelectrophoresis using fresh human serum. Japan. J. Pharmacol. 33, 403408 (1983)

21 Miyazaki, T., Oikawa, N., Yadomae, T., Yamada, H., Yamada, Y., Hong-Yen, $H$. and Ito, H.: Relationship between the chemical structure and antitumor activity of glucans prepared from Grifola umbellata. Carbohydr. Res. 69, 165-170 (1979)

22 Nakahara, W., Tokuzen, R. and Fukuoka, F.: Inhibition of mouse sarcoma 180 by a wheat hemicellulose B preparation. Nature 216, 374375 (1967)

23 Tsubura, E., Yamashita, T., Yamamoto, T. and Kagawa, K.: Biological aspects of cancer metastasis a review. Japan. J. Clin. Oncol. 11, 145-158 (1981)

24 Maeda, Y.Y. and Chihara, G.: The effect of neonatal thymectomy on the antitumor activity 
of lentinan, carboxymethyipachymaran and zymosan, and their effects on various immune responses. Int. J. Cancer 11, 153-161 (1973)

25 Ito, H. and Shimura, K.: Studies on antitumor activity of traditional Chinese medicines (1). Japan. J. Cancer Chemother. 12, 2145-2148 (1985)

26 Yamamoto, T., Yamashita, T. and Tsubura, E.: Inhibition of pulmonary metastasis of Lewis lung carcinoma by a glucan, Schizophyllan. Invasion Metastasis 1, 71-84 (1981)

27 Ito, M., lizuka, H., Masuno, T., Yasunari, R., Ogura, T., Yamamura, Y. and Azuma, I.: Killing of tumor cells in vitro by macrophages from mice given injections of squalene-treated cell wall skeleton of Nocardia rubra. Cancer Res. 41, 2925-2930 (1981)

28 Liotta, L.A., Gattozzi, C., Kleinerman, J. and Saidel, G.: Reduction of tumor cell entry into vessels by BCG-activated macrophages. Br. J. Cancer 36, 639-641 (1977)

29 Sone, S., Pollack, V.A. and Fidler, I.J.: Direct activation of tumorcidal properties in rat alveolar macrophages by Nocardia rubra cell wall skeleton. Cancer Immunol. Immunother. 9, $227-232$ (1980) 